\title{
Studies on spray pyrolyzed molybdenum trioxide thin films
}

\author{
P S PATIL and R S PATIL \\ Department of Physics, Shivaji University, Kolhapur 416004, India \\ MS received 30 January 1995; revised 12 May 1995
}

\begin{abstract}
Semiconducting molybdenum trioxide thin films have been prepared by employing simple and inexpensive spray pyrolysis technique. Films are found to be polycrystalline in nature with hexagonal phase. Optical band gap energy (direct) and room temperature electrical resistivity are of the order of $2.9 \mathrm{eV}$ and $10^{8} \mathrm{ohm}-\mathrm{cm}$, respectively. These films exhibit cathodic electrochromism.
\end{abstract}

Keywords. Molybdenum trioxide; spray pyrolysis; electrochromism.

\section{Introduction}

Electrochromic (EC) devices are of interest for smart windows in energy efficient architecture, non-emissive display devices, variable reflectance mirrors and surfaces with tunable thermal emittance (Granqvist 1992, 1993). Electrochromism was given wide spread attention through Deb's (1969) work on tungsten trioxide films. Consequently several other oxide materials based on molybdenum, nickel, cobalt, iridium, vanadium, titanium, niobium, several mixed oxides and many organic materials have been investigated for electrochromic properties.

Molybdenum trioxide $\left(\mathrm{MoO}_{3}\right)$ is a transparent, partially ionic $4 \mathrm{~d}$ transition metal oxide which has a number of interesting optical and electrical properties. Various techniques such as vacuum evaporation (Deb 1968), anodic oxidation (Arora and Kelly 1977), physical vapour deposition (Krishnakumar and Menon 1993) and spin coating (Hinokuma et al 1994) have been employed to prepare $\mathrm{MoO}_{3}$ thin films and their electrochromic and photochromic properties are reported. However no reports can be found on the preparation of $\mathrm{MoO}_{3}$ thin films by spray pyrolysis technique (SPT). SPT is a simple and inexpensive method and hence requires less capital to deposit thin films over large areas than other conventional techniques. The relative packing density of the films depends strongly on the deposition conditions. SPT also offers an advantage in controlling the structure (crystalline or amorphous) of the films.

In this paper, preparation of $\mathrm{MoO}_{3}$ thin films by spray pyrolysis technique and their structural, optical and electrical properties are reported. An attempt has been made to test the applicability of SPT to produce electrochromic $\mathrm{MoO}_{3}$ films.

\section{Experimental}

$\mathrm{MoO}_{3}$ powder (GR grade, Loba Chemie) was dissolved in ammonia solution at room temperature and doubly distilled water was added to obtain an appropriate quantity of the spraying solution. The solution was sprayed on to amorphous glass substrates maintained at $350^{\circ} \mathrm{C}$ temperature. The quantity of the solution, concentration of the solution, spray rate and time for the deposition were 50 c.c., $0.05 \mathrm{M}, 2.5 \mathrm{c.c} / \mathrm{min}$ and $20 \mathrm{~min}$ respectively. 
The film thickness was calculated by weight difference method and using the density of $\mathrm{MoO}_{3}$ based on a $100 \%$ dense film. Since the film was certainly not $100 \%$ dense, the actual thickness would therefore be somewhat higher than the given thickness. The structural identification was carried out using Philips X-ray diffractometer (PW-1710). Optical absorption measurement in the range 350 to $850 \mathrm{~nm}$ was carried out by using Hitachi 330 spectrophotometer. The two-probe method was used for d.c. electrical resistivity measurement in the temperature range 400 to $560 \mathrm{~K}$. The area of the films was defined and silver paste was applied to ensure good ohmic contacts to the film. A battery charger $(30 \mathrm{~V}, 6 \mathrm{~A})$ was used to pass current through the film and high impedance voltmeter was used for the voltage measurement across the film sample. The size of the film was $1 \times 1 \mathrm{~cm}^{2}$. To study temperature dependent resistivity measurement, strip type heaters $(65 \mathrm{~W})$ were used to heat the samples and Chromel-Alumel thermocouple was used to measure the temperature. Temperature was controlled with $\pm 2^{\circ} \mathrm{C}$ accuracy using APLAB temperature controller.

The electrochromic cell has been prepared for the study of the electrochromic characteristics. It consists of two F.T.O. coated glass plates $(10 \mathrm{ohm} / \square)$. One plate has been deposited with the $\mathrm{MoO}_{3}$ film, which acts as a working electrode and other plate as a counter electrode. Saturated calomel electrode was the reference electrode. The cell was filled with an electrolyte of $1 \mathrm{~N} \mathrm{H}_{2} \mathrm{SO}_{4}$. The electrochromic characteristics were

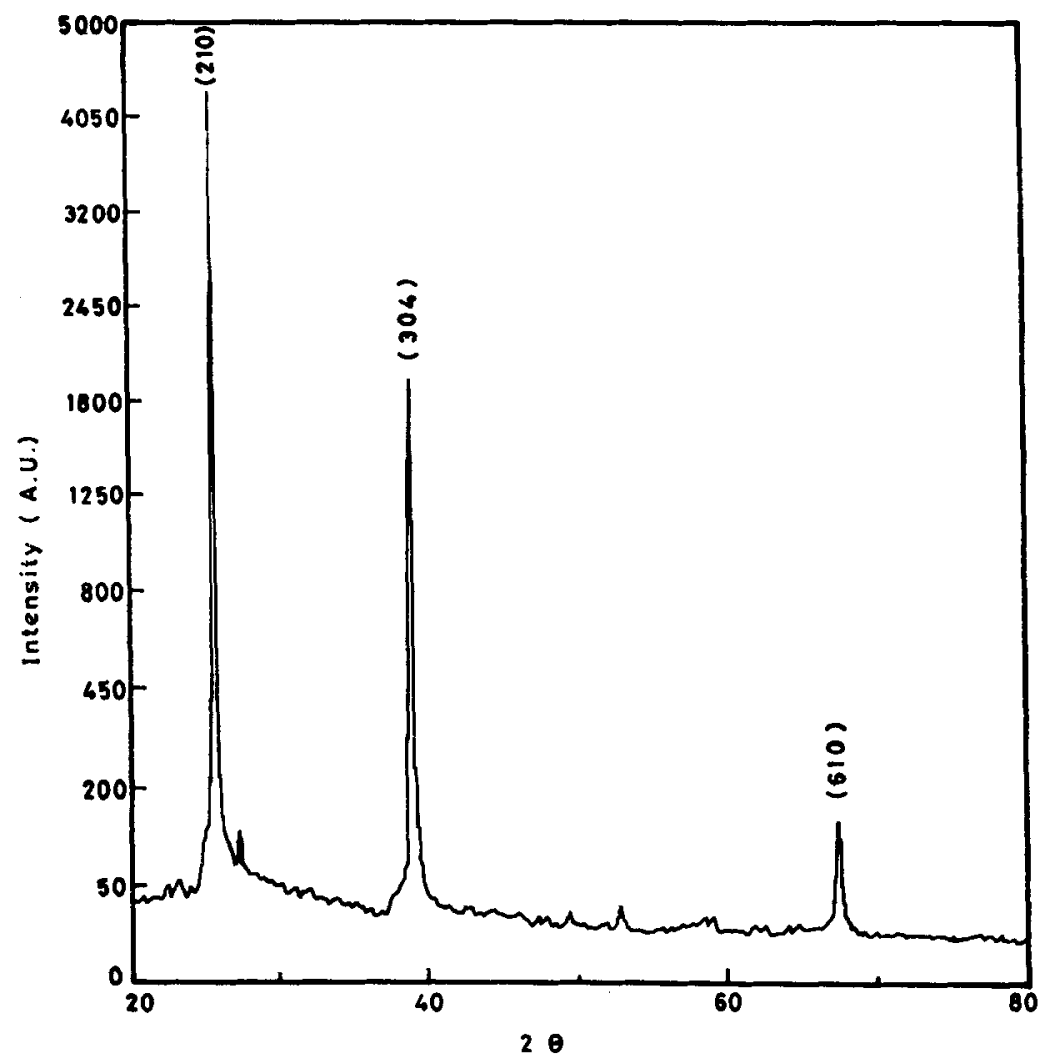

Figure 1. XRD pattern of $\mathrm{MoO}_{3}$ thin films. 
determined by using cyclic-voltammogram taken with EG and $\mathrm{G}$ model 362 potentiostat and $\mathrm{X}-\mathrm{Y}$ recorder.

\section{Results and discussion}

$\mathrm{MoO}_{3}$ powder was dissolved in ammonia solution thereby forming ammonium molybdate. The chemical reaction may be given as follows

$$
\mathrm{MoO}_{3}+2 \mathrm{NH}_{3}+\mathrm{H}_{2} \mathrm{O} \rightarrow\left(\mathrm{NH}_{4}\right)_{2} \mathrm{MoO}_{4}
$$

This solution was then sprayed on to glass substrates kept at $350^{\circ} \mathrm{C}$. The following reaction took place

$$
\left(\mathrm{NH}_{4}\right)_{2} \mathrm{MoO}_{4} \underset{350 \mathrm{C}}{\longrightarrow} \mathrm{MoO}_{3}+\mathrm{H}_{2} \mathrm{O} \uparrow+2 \mathrm{NH}_{3} \uparrow
$$

$\mathrm{MoO}_{3}$ films with $1 \cdot 1 \mu$ thickness were obtained.

Structural identification of $\mathrm{MoO}_{3}$ film was carried out using X-ray diffraction pattern of $\mathrm{MoO}_{3}$ and is shown in figure 1. It was found that films were polycrystalline in nature with hexagonal phase. Hexagonal phase is of particular relevance for electrochromism (Granqvist 1993). The spaces between the $\mathrm{MoO}_{6}$ octahedra are large enough to accommodate ions, i.e. the Mo oxide framework serves as an excellent intercalation/deintercalation host.

The observed ' $d$ ' values are in good agreement with the standard ' $d$ ' values confirming the material deposited was $\mathrm{MoO}_{3}$.

The optical density $(\alpha t)$ of the film was recorded in the wavelength range of 350 to $850 \mathrm{~nm}$ at $300 \mathrm{~K}$. The values of $\alpha$ were not corrected for the transmittance and the reflectance of the film surface. The optical data were analysed from the following classical relation for near edge optical absorption in a semiconductor,

$$
\alpha=\frac{K\left(h v-E_{\mathrm{g}}\right)^{n / 2}}{h v}
$$

where $K$ is constant, $E_{\mathrm{g}}$ is a semiconductor band gap and $n$ a constant equal to 1 for direct gap and 4 for indirect gap compound (Moss 1961).

In order to confirm the nature of optical transition in $\mathrm{MoO}_{3}$ film the plots of $(\alpha h v)^{2}$ vs $(h v)$ and $(\alpha h v)^{1 / 2}$ vs $(h v)$ were studied and shown in figure 2 . Linear portion of the curve was observed for the plot of $(\alpha h v)^{2}$ vs $(h v)$ and extrapolation of this portion to zero absorption coefficient gives optical band gap energy equal to $2.9 \mathrm{eV}$. However, estimation of band gap energy from the plot of $(x h v)^{1 / 2}$ vs $(h v)$ was outrageous. This observation therefore leads to the conclusion that optical absorption in $\mathrm{MoO}_{3}$ film takes place through direct interband transitions.

In $\mathrm{MoO}_{3}$, valence banc consists of fully occupied $\sigma$ and $\pi$ bands and the oxygen $p \pi^{+}$ levels, while $\pi^{*}$ and $\sigma^{*}$ bands are empty and constitute conduction band. The absorption edge in the spectrum of $\mathrm{MoO}_{3}$ is thus associated with the onset of promotion of electrons from $p \pi^{+}$levels in to $\pi^{*}$ band and the energy gap between valence and conduction bands is assigned a value of 2.96 eV (Deb 1968; Dickens and Neild 1968). The value of band gap energy in the present study is in good agreement with the above value. 
The room temperature electrical resistivity was of the order of $10^{8} \mathrm{ohm}-\mathrm{cm}$. The variation of resistivity with temperature in the range 400 to $560 \mathrm{~K}$ was studied. Resistivity decreases with increasing temperature showing that $\mathrm{MoO}_{3}$ film is a semiconductor. Arrhenius plot for $\mathrm{MoO}_{3}$ film is shown in figure 3. The plot shows two distinct regions, one corresponding to the low temperature region and the other corresponding to the

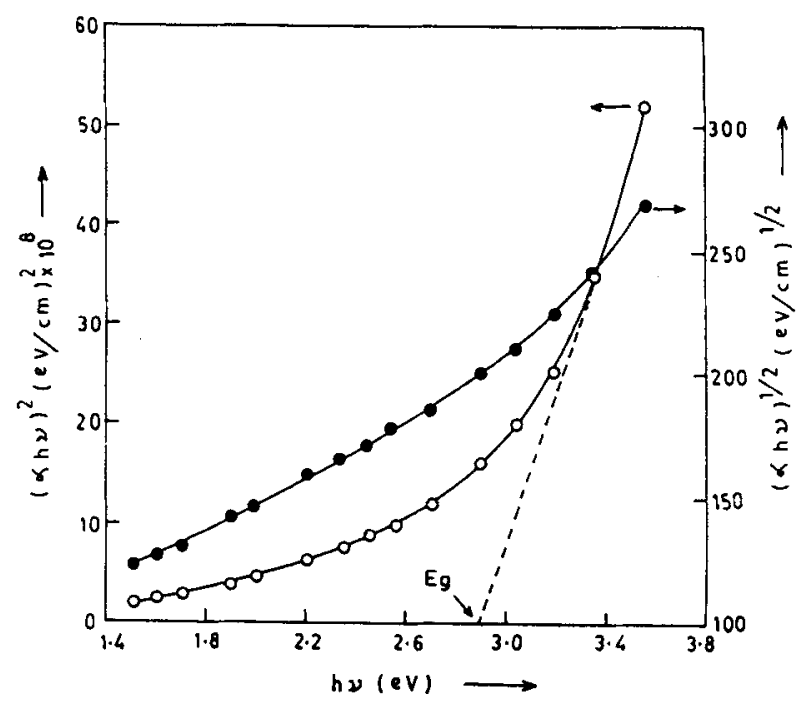

Figure 2. Plot of $(\alpha h v)^{2}$ vs $h v$ and $(\alpha h v)^{1 / 2}$ vs $h v$ for $\mathrm{MoO}_{3}$ thin film.

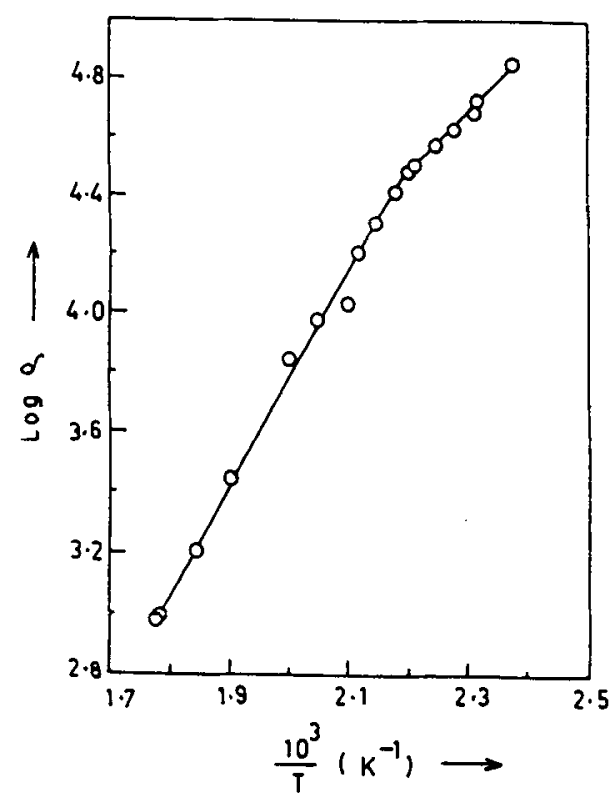

Figure 3. A plot of $\log \rho$ vs $1 / T$ for $\mathrm{MoO}_{3}$ thin film. 
high temperature region. From these two regions, activation energies $E_{\mathrm{a}}$, are calculated by using the relation,

$$
\rho=\rho_{0} \exp \left(-E_{\mathrm{a}} / k T\right)
$$

where $\rho_{0}$ is the pre-exponential factor, $k$ the Boltzmann's constant and $T$ the absolute temperature. In high temperature region, $E_{\mathrm{a}}$ is of the order of $0.29 \mathrm{eV}$ and in low temperature region it is of the order of $0.19 \mathrm{eV}$ and represents the average energy of the carriers with respect to the Fermi energy, if the carriers can only move at the bottom or top of the well defined band. Similar results have been reported by others for vacuum evaporated (Deb 1968) and physical vapour deposited (Krishnakumar and Menon 1993) thin films.

Figure 4 shows cyclic-voltammogram of the FTO/MoO $/ \mathrm{M}_{3} / \mathrm{H}_{2} \mathrm{SO}_{4} / \mathrm{FTO}$ Cell. In cyclicvoltammogram a voltage between the working electrode and counter electrode is swept back and forth between two setpoints with scan rate $200 \mathrm{mV} / \mathrm{sec}$, and the electrical currents associated with ion intercalation/deintercalation are measured. When a voltage of about $+0.25 \mathrm{~V}$ (SCE) is applied, cathodic current flows and the film rapidly switched from transparent to a deep blue, indicating that $\mathrm{H}^{+}$ions are intercalating into $\mathrm{MoO}_{3}$ as it is being reduced. Anodic íbleaching) current starts $\sim 500 \mathrm{mV}$ after reversal of the potential scan. The compleie bleaching of the film occurs within $40 \mathrm{sec}$. The electrochromic electrode is reoxidized and deintercalates $\mathrm{H}^{+}$. The coloration-bleaching process may be expressed by

$$
\underset{\text { (Transparent) }}{\mathrm{MoO}_{3}+x \mathrm{H}^{+}+x \mathrm{e}^{-}} \rightleftharpoons \underset{\text { (deep blue) }}{\mathrm{H}_{x} \mathrm{MoO}_{3}} .
$$

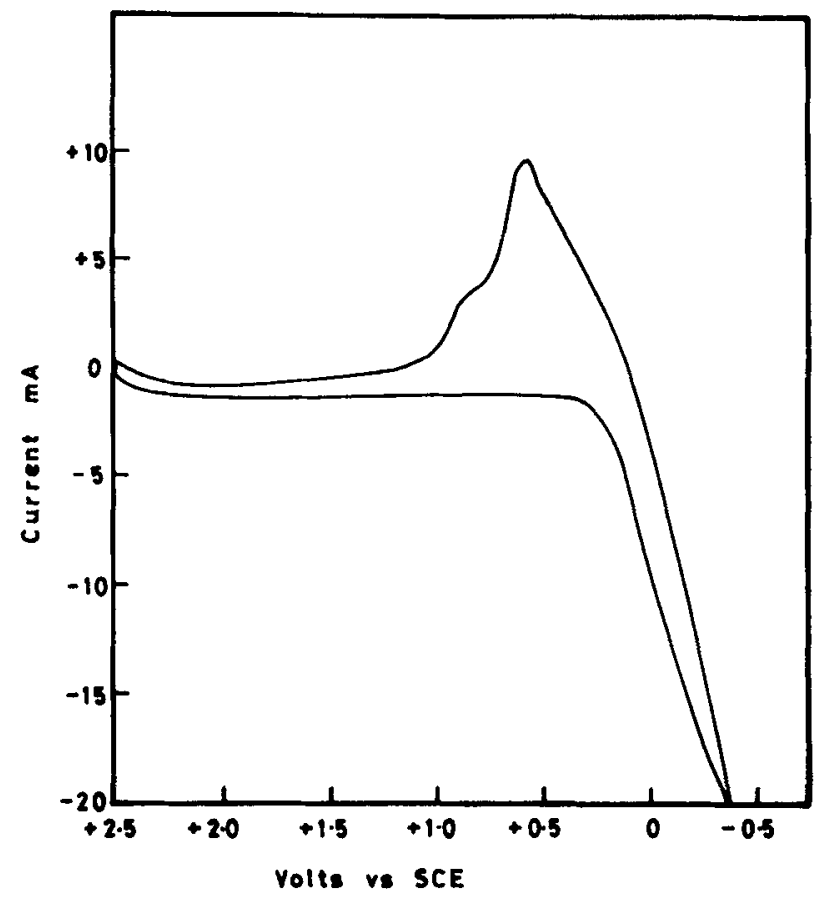

Figure 4. Cyclic-voltammogram of electrochromic cell formed with $\mathrm{MoO}_{3}$ film. 


\section{Conclusions}

Semiconducting molybdenum oxide thin films were deposited by spray pyrolysis technique on to the glass substrates. Films were polycrystalline in nature with hexagonal phase. The optical band gap energy (direct) was $2.9 \mathrm{eV}$. Values of activation energies were 0.29 and $0.19 \mathrm{eV}$ for high and low temperature regions respectively. The as-deposited films were transparent and switched to a deep blue on application of about $+0.25 \mathrm{~V}$ (SCE) thereby exhibit electrochromism.

\section{Acknowledgement}

One of the authors (RSP) wishes to thank the University Grants Commission, New Delhi, for the award of a Teacher Fellowship.

\section{References}

Arora M R and Roger Kelly 1977 J. Electrochem. Soc. 1241493

Deb S K 1968 Proc. R. Soc. A304 211

Deb S K 1969 Appl. Opt. Suppl. 3192

Dickens P G and Neild D J 1968 Trans. Faraday Soc. 6413

Granquist C G 1992 Solid State Ionics 47953

Granquist C G 1993 Physics of thin films (San Diego: Academic) Vol. 17 p. 301

Hinokuma K, Kishimoto A and Kudo T 1994 J. Electrochem. Soc. 141876

Krishnakumar S K and Menon C S 1993 Bull. Mater. Sci. 16187

Moss T S 1961 Optical properties of semiconductors (London: Butterworths) p. 34 